\title{
Relationship between internet self-efficacy and internet anxiety: A nuanced approach to understanding the connection
}

\author{
Narmada Paul and Michael Glassman \\ The Ohio State University
}

\begin{abstract}
The present study makes the case that the individual constituents of internet self-efficacy - search self-efficacy, communication self-efficacy, organisation self-efficacy, differentiation selfefficacy, and reactive/generative self-efficacy - may be of differential importance in predicting internet anxiety within web-assisted learning environments. Two hundred and eighty-nine undergraduate students enrolled in a blog-centric general education course on child development at a large mid-western university in the United States participated in this study. Based on inferences drawn from the socio-cognitive perspective and cognitive load theory, it was hypothesised that in a blog-centric constructivist learning environment, reactive/generative selfefficacy or the belief in one's ability to react meaningfully to others' posts and generate educationally valuable posts, would emerge as a unique predictor of internet anxiety after controlling for all of the other facets of internet self-efficacy. The results of a two-step hierarchical regression indicated that both reactive/generative self-efficacy and search selfefficacy are unique predictors of internet anxiety. The findings have several implications for researchers seeking greater insight into the relationship between internet self-efficacy and internet anxiety as well as instructors seeking to create a constructivist learning environment utilising the potential of the web.
\end{abstract}

\section{Introduction}

There are a number of complex issues involved in integrating internet-based tools with face-to-face classroom activities - some at the institutional level, some at the classroom level, and some at the individual level. At the individual level, there are differences in internet self-efficacy or students' perceptions of their skills and abilities in being able to use the internet successfully as a learning tool and a knowledge sharing medium (Glassman \& Kang, 2012). The conceptualisation by various researchers, of internet self-efficacy as a multi-faceted global construct is strongly dependent on the user experience within a given context (Tsai, Chuang, Liang, \& Tsai, 2011). Another less discussed but equally important of these individual differences is internet anxiety; a fear of using the internet for constructive learning purposes. It has been borne out by research that internet self-efficacy, long thought to be an important element for successful internet use (Liang \& Tsai, 2008; Tsai \& Tsai, 2003; Wu \& Tsai, 2006), and internet anxiety move in opposite directions (Kim \& Glassman, 2013). Internet anxiety can be a barrier to the students' educational experience in newly emerging learning environments where webbased tasks constitute a vital component of course activities. Identifying the ways in which these individual differences affect the processes and the outcomes of internet-infused education is especially important when instructors adopt a constructivist approach and create a learning environment chiefly characterised by knowledge sharing on the web. Specifically, given that the use of online course management systems is becoming increasingly popular in higher education (Charlton \& Morahan-Martin, 2012), understanding the factors that predict internet anxiety is crucial in order to plan strategies to minimise it and to promote active participation among students in web-assisted learning environments. Internet self-efficacy often correlates negatively with internet anxiety (Compeau \& Higgins, 1995; Eastin \& La Rose, 2000), therefore a possible strategy to reduce internet anxiety in students is to increase their level of internet self-efficacy. The objective of the current study was to determine the relative importance of the individual constituents of internet selfefficacy in predicting internet anxiety within a web-assisted learning environment. In particular, it was proposed that the distinct constituents of internet self-efficacy may demonstrate differential potencies in being able to predict internet anxiety in a blog-centric course. The results enhance current understanding of the impact the individual elements of internet self-efficacy have on internet anxiety. 


\section{The constructivist web-assisted learning environment}

Constructivism has its roots in Vygotsky's views on learning and continues to guide many educational researchers' conception of optimal learning environments (Glassman, 1996). Researchers working within this paradigm view knowledge construction as an exploratory process, where learners actively engage with their immediate ecology, individually as well as collectively, as they build more nuanced understandings of their worlds. This is different from other cognitive paradigms such as information processing approach which focuses on information encoding and retrieval strategies only at the level of the individual learner and nativism which puts an emphasis on individual hereditary causes as determinants of learning (Gardner, 2008). The web offers possibilities for implementing constructivist ideas in education by enabling new kinds of cooperative and/or collaborative activities. It allows students to engage in dialogue and share a variety of educational resources with each other outside the confines of the classroom (Du \& Wagner, 2007). Application of constructivist principles to web-assisted learning environments is a fairly recent phenomenon; however, it is often mistakenly assumed that incorporating web-based activities will easily lead to co-creation of knowledge among learners (Chuang \& Tsai, 2005; Tsai, 2008). This misplaced assumption overlooks the role played by students' psychological characteristics in co-construction of knowledge on online platforms. This study highlights the importance of understanding the relationships among students' psychological characteristics that can facilitate co-construction of knowledge within web-assisted learning environments.

\section{The significance of internet anxiety: A socio-cognitive perspective}

Bandura's (1986, 1994, 1997, 2006) socio-cognitive theory considers human beings as active agents in the learning process, as opposed to the behaviouristic view where human beings are passive and subject to environmental forces. It is relevant to point out in this context that, Bandura (1997) considered anxiety (i.e., a state of arousal) regarding a task to be related to an individual's self-efficacy or beliefs about the ability to accomplish that task successfully; specifically, self-efficacy and anxiety are negatively related to each other. In the present study, the socio-cognitive perspective offers a theoretical basis for understanding the relationship between internet self-efficacy and internet anxiety and bolsters the significance of internet anxiety as a psychological process in web-assisted learning environments.

The conceptualisation of internet anxiety emerged from early investigations on computer anxiety (e.g., Heinssen, Glass, \& Knight, 1987). In the 1990s, the inception of the internet brought on a drastic change in the utility and application of computers. In recognition of these developments, Presno (1998) explored the idea of internet anxiety within the broader domain of computer anxiety and identified four areas of internet anxiety: internet terminology anxiety, net search anxiety, internet delay anxiety, and general fear of internet failure. Soon after, Chou (2003) noted that internet anxiety should be acknowledged as a construct distinct from computer anxiety. Furthermore, Chou observed that the internet's interactivity feature has two aspects: humancomputer and interpersonal. While the human-computer aspect revolves around the technical facet of internet use, the interpersonal aspect focuses on the complexities of person-to-person online interaction. The interpersonal aspect of interactivity is of particular relevance to the context of the present study.

When speaking about internet anxiety, our focus is not on the physical use of internet devices but instead on the more complex and human aspects of internet use, connectivity, and the internetworking of ideas. For instance, how anxious people are about putting their thinking online as permanent markers to be read by others. As individuals' use of the internet matures, they engage in establishing a fuller social, emotional , and cognitive presence; this complex nature of engagement can create higher levels of anxiety (Glassman, 2016). According to Glassman, this can be especially true in academic settings where students are used to writing only for the teacher. In this connection, it is pertinent to note that existing research suggests that the context of internet use strongly influences whether a person experiences internet anxiety (Aydin, 2011). The nature of activities included by the instructor in a web-assisted learning context determines the specific abilities students will need to be successful. Consequently, in our study we define Internet anxiety as the apprehension experienced by a student at the prospect of using the internet for knowledge building within constructivist learning environments supported by blogs. Applying Bandura’s (1988) socio-cognitive theory, learners who believe that the demands 
of the web-based activities exceed their self-perceived capabilities (i.e., they have low internet self-efficacy) are more likely to experience internet anxiety. Conversely, the learners who believe that they have the prerequisite skills to meet the demands (i.e., they have high internet self-efficacy) will be less likely to experience internet anxiety.

Internet anxiety can be a hindrance to the success of students in the face of rapid integration of information communication technology (ICT) in education (Kim \& Glassman, 2013; Presno, 1998). Within the sociocognitive framework, anxiety has typically been conceived as a three-pronged experience affecting thought, physiological state, and behaviour (Bandura, 1988; Lang, 1977). Thus, students with internet anxiety may experience maladaptive thought processes (e.g., “I don't have the skills needed to do this task”), suffer physical discomfort (e.g., racing heartbeat), and refrain from internet use altogether (e.g., avoiding use of internet for educational purposes). In fact, research has illustrated several detrimental effects that can accompany internet anxiety and impact student learning. Negative self-evaluative thoughts accompanying internet anxiety can interrupt a student's task-related cognitive processing because attentional resources are spent trying to suppress intrusive thoughts instead of performing the actual task (Derakshan \& Eysenck, 2009). The behavioural component of anxiety (i.e., avoidance behaviour) is of special concern from a socio-cognitive viewpoint because high levels of internet anxiety leads to lowered internet use (i.e., avoidance behaviour) as illustrated through empirical research (Brosnan et al., 2012; Joiner, Brosnan, Duffield, Gavin, \& Maras, 2007; Joiner, et al., 2005; Rezai \& Shams, 2014; Susskind, 2004). Avoiding internet use in educational contexts lowers the chances of gaining mastery experiences (i.e., actual experience of success) which can elevate internet selfefficacy making it a vicious repetitive cycle (Bandura, 1977). In short, given that internet use in education fosters motivation to learn, improves verbal communication, and encourages creative thinking (Cheung \& Huang, 2005), if the relationship between internet self-efficacy and internet anxiety is neglected, anxious students will be at a continuous learning disadvantage (Brosnan et al., 2012).

\section{Internet self-efficacy: A closer look at the constituents}

Tsai et al. (2011) observe that internet self-efficacy has been conceptualised in slightly different ways depending on the nature of web-assisted learning environment within which it is being studied (e.g., Peng, Tsai, \& Wu, 2006; Torkzadeh \& van Dyke, 2001; Wu \& Tsai, 2006). In this study, Kim and Glassman’s (2013) approach to understanding internet self-efficacy in face-to-face learning environments integrating the use of blogs was used. Based on students' responses to Likert type items, Kim and Glassman developed an internet self-efficacy scale (ISS) and used factor analysis to illustrate that internet self-efficacy has five dimensions: (a) beliefs about one's ability to communicate online with others (communication self-efficacy); (b) beliefs about one's ability to search for information online (search self-efficacy); (c) beliefs about one's ability to organise the vast multitude of online information (organisation self-efficacy); (d) beliefs about one's ability to differentiate among online information on the basis of quality (differentiation self-efficacy); and (e) beliefs about one's ability to react to information published online by others (i.e., reactive ability) and generate educationally valuable information (i.e., generative ability) to contribute to the online knowledge building process (collectively labeled as reactive/generative self-efficacy). Though the dimensions are significantly correlated (Table 1), low to moderate correlations indicate they are distinct. The distinct elements constituting the construct are just as important as the global construct itself and deserve acknowledgement. The present study emphasises that depending on the nature of the learning environment some of these elements may be more pivotal than others in predicting internet anxiety. 
Table 1

Correlation among the dimensions of internet self-efficacy

\begin{tabular}{lccccc}
\hline $\begin{array}{l}\text { Dimensions of } \\
\text { internet self- } \\
\text { efficacy }\end{array}$ & $\begin{array}{c}\text { Search } \\
\text { self- } \\
\text { efficacy }\end{array}$ & $\begin{array}{c}\text { Communication } \\
\text { self-efficacy }\end{array}$ & $\begin{array}{c}\text { Organisation } \\
\text { self-efficacy }\end{array}$ & $\begin{array}{c}\text { Differentiation } \\
\text { self-efficacy }\end{array}$ & $\begin{array}{c}\text { Reactive/generative } \\
\text { self-efficacy }\end{array}$ \\
\hline $\begin{array}{l}\text { Search self-efficacy } \\
\text { Communication }\end{array}$ & $.38^{* *}$ & $.51^{* *}$ & $.47^{* *}$ & $.37^{* *}$ \\
$\begin{array}{l}\text { self-efficacy } \\
\begin{array}{l}\text { Organisation self- } \\
\text { efficacy }\end{array}\end{array}$ & & $.41^{* *}$ & $.39^{* *}$ & $.43^{* *}$ \\
$\begin{array}{l}\text { Differentiation self- } \\
\text { efficacy }\end{array}$ & & & $.51^{* *}$ & $.44^{* *}$ \\
$\begin{array}{l}\text { Reactive/generative } \\
\text { self-efficacy }\end{array}$ & & & & $.50^{* *}$ \\
\hline
\end{tabular}

Note. ${ }^{* *} p<.01$

\section{The unique role of reactive/generative self-efficacy}

The ability to react to information created by others and generate new information that is of educational value to others was presumed to be especially important in the present study. That is, in a learning environment where students are expected to contribute to the class blog and respond to the blog posts of their peers, reactive/generative self-efficacy should play a unique role in predicting Internet anxiety over and above the other constituents of internet self-efficacy. From a socio-cognitive view, the demands of such a learning environment will produce high internet anxiety in learners with low reactive/generative self-efficacy and low internet anxiety in learners with high reactive/generative self-efficacy. Existing literature suggests that blogging in educational contexts makes learners worried about being able to judge the accuracy of information posted by others, fear negative evaluation of their own posts, and feel apprehensive about expressing dissent publicly (Cowan, Vigentini, \& Jack, 2009; Ebner, Zechner, \& Holzinger, 2006). In the light of this evidence, it is fair to say that reactive/generative self-efficacy will help learners overcome worry and apprehension associated with internet anxiety in blog-centric classes.

\section{The underlying complexity of reactive/generative skills}

There is another major reason this study focuses on examining the unique role of reactive/generative selfefficacy in relation to internet anxiety; quite possibly, reactive/generative skills are uniquely complex in comparison to other Internet skills. Kim and Glassman (2013) raise the possibility that these skills are a novel experience for most learners and entail considerable cognitive challenge. The socio-cognitive theory and the cognitive load theory allow for a deeper understanding of the reasons that make it harder for students to develop reactive/generative self-efficacy compared to self-efficacy pertaining to other internet related skills.

\section{The socio-cognitive view}

Bandura's (1977) socio-cognitive theory emphasises human agency in the learning process and identifies actual performance accomplishments or mastery experiences as a significant determinant of self-efficacy. In other words, self-efficacy regarding a specific task is a result of having had successful experiences with that particular task in the past. The relationship between mastery experience and self-efficacy can shed light on the underlying complexity of reactive/generative self-efficacy.

The ability to react to others' contributions and generate one's own content online is potentially the most important indicator of collective intelligence in collaborative online contexts (O'Reilly, 2005). Echoing this line of thought, Glassman and Kang (2012) proposed a concept called open source intelligence (OSINT) to pinpoint skills essential to intelligent problem solving through the internet - communication skills, search skills, differentiation skills, organisation skills, and reactive/generative skills. According to Glassman and Kang, there 
are two reasons why self-efficacy with respect to reactive/generative skills is possibly the most difficult to develop: (a) the extension of individual thought processes into a collective information universe poses a greater intellectual challenge than processing information at the individual level; and (b) the tools that call for the application of collective intelligence have not been implemented in educational contexts extensively and therefore most students' have not had adequate opportunities to practice reactive/generative skills. This implies that reactive/generative skills are uniquely challenging to implement in web-assisted constructivist learning environments because they are cognitively demanding and their use in educational settings is still quite novel; both of these reasons quite possibly hinder the experience of mastery that is so essential to development of selfefficacy.

It is important to note, empirical research shows that students have lower levels of reactive/generative selfefficacy compared to self-efficacy pertaining to other Internet related skills (Kim \& Glassman, 2013). Kim and Glassman categorised the dimensions of internet self-efficacy into distinct levels; based on theory and research (Benkler, 2006; Castells, 2007; Castells, Tubella, Sancho, Diaz ed Isla, \& Wellman, 2004; Glassman \& Kang, 2012) they divided the five types of internet skills into three levels based on probability of students having had prior experience in implementing them for web-based activities. If a skill has been used extensively in the past, students will very likely believe that they will be able to apply those skills whenever needed. On the other hand, students are less likely to feel efficacious about using internet skills which are used rarely in their everyday lives. Kim and Glassman's study found that students scored lowest on reactive/generative self-efficacy, highest on search self-efficacy and communication self-efficacy, and in between on differentiation self-efficacy and organisation self-efficacy. This implies that reactive/generative skills are less used in everyday activities of the students, leading to fewer (if any) chances for mastery experiences that are so critical for sustained self-efficacy.

\section{Argumentation and cognitive load}

When learners are collaborating on an online platform to co-create knowledge using reactive/generative skills, there is an expectation that the process will involve argumentative discourse. The process of argumentation involves two strategies that must be employed simultaneously: (a) framing a response to what one's peers are saying after processing and evaluating the content of their posts; and (b) expressing one's own point of view with reasons (Kuhn \& Udell, 2007). Kuhn and Udell found that most people tend to elaborate on the argument that favours their own position and neglect opposing arguments altogether, simply because it is cognitively challenging to engage in both of these interdependent processes simultaneously. These processes are highly comparable to the skills of reaction and generation as defined in this study.

Focusing on both reaction and generation at the same time can overwhelm a novice learner because the chances of experiencing cognitive overload are high. Sweller, Van Merrienboer, and Paas (1998) conceptualise cognitive overload as a situation where the demands of a task exceeds the capacity of the learner. To be more precise, from a cognitive load perspective, this indicates that the intrinsic cognitive load or the cognitive demands (i.e., reaction/generation) that are associated with the inherent nature of the task (i.e., blogging) excluding all other factors (germane or extraneous), is quite high. According to Kuhn and Udell (2007), the capacity to deal with higher levels of intrinsic load increases with expertise. This would imply that students who are new to blogging within a constructivist environment may not have the expertise in the beginning, making it hard for them to start out with high levels of reactive/generative self-efficacy.

\section{Research hypothesis}

It is clear from the reviewed literature that reactive/generative self-efficacy is of particular significance in webassisted learning environments such as the blog-centric course in this study, with an emphasis on coconstruction of knowledge through online dialogue. In particular, reactive/generative skills are cognitively challenging (Glassman \& Kang, 2012; Sweller et al., 1998) and there is a dearth of opportunities to exercise these skills in educational contexts (Kim \& Glassman, 2013). Additionally, due to a paucity of experiences that could help develop these skills, a situation is created where mastery experiences crucial for building reactive/generative self-efficacy are quite rare at present. According to the socio-cognitive perspective 
(Bandura, 1977), self-efficacy is inversely related to anxiety. Based on this, we hypothesise that that reactive/generative self-efficacy will be negatively related to internet anxiety. Furthermore, cognitive load theory (Sweller et al., 1998) serves as a viable rationale in explaining the unique cognitive complexity of reactive/generative skills compared to other internet related skills. This leads us to expect that reactive/generative self-efficacy will be a unique predictor of the variance in internet anxiety over and above communication self-efficacy, search self-efficacy, organisation self-efficacy, and differentiation self-efficacy. Statistically speaking, it is hypothesised that reactive/generative self-efficacy will predict internet anxiety after controlling for communication self-efficacy, search self-efficacy, organisation self-efficacy, and differentiation self-efficacy.

Hierarchical regression was chosen as the method of analysis in order to test the research hypothesis since it allows us to examine the differential effect of the distinct predictors on the outcome variable in a systematic way. This statistical approach is an especially apt choice when testing a hypothesis based on theoretical implications that suggest that that certain predictors may have unique effects on the outcome controlling for other predictors in the regression model. In our case, the constituents of internet self-efficacy - communication self-efficacy, search self-efficacy, organisation self-efficacy, differentiation self-efficacy, and reactive/generative self-efficacy - were treated as distinct predictors of the outcome variable, internet anxiety.

\section{Method}

\section{Participants}

The sample consisted of 289 undergraduate students at a large mid-western university in the United States. There were 35 male students (12.1\%) and 254 female students (87.9\%). The mean age of the sample was 20.49 years with a standard deviation of 4.02 years. Two-hundred and eighty students (96.9\%) among the participants were native speakers of English and 9 students (3.1\%) in the sample were international students, who were nonnative English speakers.

\section{Procedure}

The participants were recruited from general education classes over two consecutive academic quarters. All of them were enrolled in a blog-centric child development course. There were two blogging components in the curriculum: individual blogging and group blogging.

Individual blogging required students’ involvement in insightful discussion regarding topics connected to early childhood development, hyperlinking to high quality sources of information to support their viewpoints. This component demanded independent thinking. Students were evaluated on the basis of the quality of their online communication as opposed to the quantity or consistency of individual blogging. Students were given a guideline for effective blogging practices beforehand. Instructors specifically commented on interesting blog posts only.

Group blogging required students to collaborate with each other. Every week, students engaged in a group activity which required them to apply concepts they were learning in class. After finishing the activity, they were required to post a single blog as a group to share their work with the larger community of learners. Students were evaluated on the basis of their creative effort, accuracy and relevance of the information posted.

At the beginning of each quarter, students' internet self-efficacy (search self-efficacy, communication selfefficacy, organisation self-efficacy, differentiation self-efficacy, reactive/generative self-efficacy) was measured. After 2 weeks of extensive use of the internet for their work, their internet anxiety was assessed. 


\section{Measures}

We used Kim and Glassman's (2013) approach to operationalise the distinct elements of internet anxiety. Internet self-efficacy was measured using the 17 item internet self-efficacy scale (ISS) (Kim \& Glassman, 2013) consisting of five sub-scales (see Appendix A): communication self-efficacy (two items; e.g., "I can use social networking sites as an effective way of connecting with others"); search self-efficacy (two items; e.g., "I can use the internet to help me find good information about children and their development”); organisation selfefficacy (three items; e.g., "I can organise the information I find on the internet so that it is coherent and answers specific questions”); differentiation self-efficacy (four items; e.g., "I can use hyperlinks to find information that is important to me”); and reactive/generative self-efficacy (six items; e.g., "I can offer other people important and interesting information by posting on the internet"). Participants indicated on a scale of 1 (not at all confident) to 7 (very confident) the extent to which they believed that they could perform each described task successfully. The Cronbach's alphas were .91, .90, .88, .83, and .78 for reactive/generative self-efficacy, differentiation self-efficacy, organisation self-efficacy, communication self-efficacy, and search self-efficacy, respectively.

As noted in the literature review, the operationalisation of internet anxiety in this study is different compared to other researchers who have measured the construct in the past (e.g., Chou, 2003). Our focus is on the anxiety accompanying the person-to-person online interaction as opposed to the technical use of the internet. Internet anxiety was assessed using the internet anxiety scale (IAS) (Kim \& Glassman, 2013) which is essentially a modified version of the state-trait anxiety inventory (STAI) (Speilberger, Vagg, Barker, Donham, \& Westberry, 1980). Spielberger et al. (1980) suggest that the items of the original scale can be modified to accurately measure anxiety experienced in a specific situation. The STAI items were adapted by Kim and Glassman (2013) to be suitable for use within the blog-centric course context. The scale consisted of 20 items (e.g., "I feel strained having to write online every week"; see Appendix B). The participants reported how they felt on a scale of 1 (not at all) to 4 (very much so). The Cronbach's alpha was .86.

\section{Results}

\section{Missing data}

The data set consisted of missing data for 13 items on the ISS. The percentage of missing values on each of these items was $1 \%$ or less. All the items on the internet anxiety scale had missing values. The percentage of missing values on each of these items was $12.4 \%$ or less. Multiple imputation was conducted to account for the missing data on SPSS 21. The automatic method and linear regression model was used to complete multiple imputation. The data set used for analysis consisted of 289 students after imputation.

\section{Two-step hierarchical regression}

To test the hypothesis, a two-step hierarchical regression was conducted. Two prediction models were tested to examine whether reactive/generative self-efficacy contributed uniquely to the explanation of the total variance in internet anxiety over and above the other predictors (communication self-efficacy, search self-efficacy, organisation self-efficacy, and differentiation self-efficacy). Gender was treated as a control variable in both the prediction models.

The descriptive statistics of the variables in the model are included in Table 2. Table 3 and Table 4 indicate that multicollinearity among the predictors is not a concern in the current analysis as indicated by the tolerance and variance inflation factor values for the predictors in model one and model two. 
Table 2

Descriptive statistics of variables in the prediction model

\begin{tabular}{lccccc}
\hline Variables & Mean & Maximum & Minimum & Standard deviation & Variance \\
\hline Search self-efficacy & 12.55 & 14 & 6 & 1.56 & 2.43 \\
Communication self-efficacy & 12.54 & 14 & 2 & 1.99 & 3.95 \\
Organisation self-efficacy & 17.58 & 21 & 3 & 3.02 & 9.11 \\
Differentiation self-efficacy & 21.15 & 28 & 4 & 4.70 & 22.05 \\
Reactive/generative self-efficacy & 28.52 & 42 & 7 & 7.33 & 53.82 \\
Internet anxiety & 36.14 & 71 & 20 & 8.83 & 77.90 \\
\hline
\end{tabular}

Table 3

Tolerance and variance inflation factor values of predictors in model one

\begin{tabular}{lcc}
\hline Variables & Tolerance & Variance inflation factor \\
\hline Search self-efficacy & .67 & 1.5 \\
Communication self-efficacy & .76 & 1.3 \\
Organisation self-efficacy & .62 & 1.5 \\
Differentiation self-efficacy & .66 & 1.5 \\
\hline
\end{tabular}

Table 4

Tolerance and variance inflation factor values of predictors in model two

\begin{tabular}{lcc}
\hline Variables & Tolerance & Variance inflation factor \\
\hline Search self-efficacy & .66 & 1.5 \\
Communication self-efficacy & .73 & 1.4 \\
Organisation self-efficacy & .61 & 1.6 \\
Differentiation self-efficacy & .61 & 1.6 \\
Reactive/generative self-efficacy & .65 & 1.5 \\
\hline
\end{tabular}

\section{Model one}

The following constituents of internet self-efficacy were included as predictors in the first regression model (model one) - communication self-efficacy, search self-efficacy, organisation self-efficacy, and differentiation self-efficacy. To control for the effect of gender on internet anxiety, gender was included as a predictor in the model.

As illustrated in Table 5, model one was significant and explained 8\% of the variance in internet anxiety $\left(R^{2}=\right.$ $\left.0.08, F_{(5,283)}=4.95, p<.05\right)$. The $\beta$ weights in model one are given in Table 6 . Search self-efficacy was the only significant predictor in model one $(\beta=-0.16, t=-2.35, p<.05)$. That is, search self-efficacy is a unique predictor of internet anxiety after controlling for all the other predictors in model one: gender, communication selfefficacy, differentiation self-efficacy, and organisation self-efficacy. Gender, communication self-efficacy, organisation self-efficacy, and differentiation self-efficacy were not significant predictors in model one.

Table 5

Proportion of explained variance in model one and model two

\begin{tabular}{lccc}
\hline Model & Variance explained $\left(R^{2}\right)$ & Critical value $(F)$ & Level of significance $(p)$ \\
\hline Model one & .080 & 4.95 & .000 \\
Model two & .106 & 5.55 & .000 \\
\hline
\end{tabular}


Table 6

Regression coefficients in model one

\begin{tabular}{lccc}
\hline Predictors & $\begin{array}{c}\text { Regression coefficient } \\
(\beta)\end{array}$ & Critical value $(t)$ & Level of significance $(p)$ \\
\hline $\begin{array}{l}\text { Gender } \\
\text { Search self-efficacy }\end{array}$ & .01 & .22 & .83 \\
$\begin{array}{l}\text { Communication self- } \\
\text { efficacy }\end{array}$ & -.16 & -2.35 & .02 \\
$\begin{array}{l}\text { Organisation self- } \\
\text { efficacy }\end{array}$ & -.08 & -1.23 & .22 \\
$\begin{array}{l}\text { Differentiation self- } \\
\text { efficacy }\end{array}$ & -.07 & -.91 & .36 \\
\hline
\end{tabular}

\section{Model two}

In model two, reactive/generative self-efficacy was included in the prediction model along with the same set of predictors used in model one: gender, search self-efficacy, communication self-efficacy, differentiation selfefficacy, and organisation self-efficacy. Using this statistical approach allowed for observing the unique role played by reactive/generative self-efficacy in explaining the variance in internet anxiety.

As shown in Table 5, model two was significant and explained $10.6 \%$ of the variance in internet anxiety $\left(R^{2}=\right.$ $\left..106, F_{(6,282)}=5.55, p<.05\right)$. Including reactive/generative self-efficacy in addition to gender, search selfefficacy, communication self-efficacy, differentiation self-efficacy, and organisation self-efficacy, as predictors in the model did make a significant impact in explaining the total variance in internet anxiety as indicated in Table $5\left(\Delta R^{2}=.025, F_{(1,282)}=, p<.05\right)$. That is, after incorporating reactive/generative self-efficacy the prediction model was explaining an additional $2.5 \%$ of the variance in Internet anxiety compared to model one and this increase in explained variance was significant.

In model two, the $\beta$-weights in Table 7 indicate that reactive/generative self-efficacy and search self-efficacy are unique predictors of internet self-efficacy. When reactive/generative self-efficacy increases by one unit controlling for all other predictors in the model, internet anxiety decreases by -.20 units and this is a significant decrease $(\beta=-.20, t=-2.82, p<.05)$. When search self-efficacy increases by one unit controlling for all other predictors in the model, internet anxiety decreases by -.15 units and this is a significant decrease $(\beta=-.15, t=$ $-2.2, p<.05)$. Gender, communication self-efficacy, organisation self-efficacy, and differentiation self-efficacy were not significant as predictors in model two.

Table 7

Regression coefficients in model two

\begin{tabular}{lccc}
\hline Predictors & $\begin{array}{c}\text { Regression coefficient } \\
(\beta)\end{array}$ & Critical value $(t)$ & Level of significance $(p)$ \\
\hline Gender & -.001 & -.02 & .98 \\
Search self-efficacy & -.15 & -2.2 & .03 \\
$\begin{array}{l}\text { Communication self- } \\
\text { efficacy }\end{array}$ & -.04 & -.58 & .57 \\
$\begin{array}{l}\text { Organisation self-efficacy } \\
\begin{array}{l}\text { Differentiation self- } \\
\text { efficacy }\end{array}\end{array}$ Reactive/generative self- $^{\text {efficacy }}$ & -.03 & -.45 & .65 \\
\hline
\end{tabular}




\section{Discussion}

The hypothesis, reactive/generative self-efficacy predicts internet anxiety after controlling for all of the other elements of internet self-efficacy (communication self-efficacy, search self-efficacy, organisation self-efficacy, and differentiation self-efficacy) was supported by the results of the hierarchical regression analysis. That is, reactive/generative self-efficacy uniquely accounted toward the percentage of explained variance in internet anxiety scores over and above the other predictors in the blog-centric learning environment. Interestingly, search self-efficacy also emerged as a unique predictor of internet anxiety indicating that, it is also a relevant constituent of Internet self-efficacy as far as prediction of Internet anxiety in a blog-centric learning environment is concerned. The overarching argument guiding our research, that not all elements of internet self-efficacy are equally important in all types of web-assisted learning environments, is supported through the results showing that the three remaining elements of internet self-efficacy (communication self-efficacy, organisation self-efficacy, and differentiation self-efficacy) were not significant predictors of internet anxiety in the blog-centric class.

\section{Reactive/generative self-efficacy}

Reactive/generative self-efficacy was negatively related to internet anxiety. That is, the higher a student's reactive/generative self-efficacy, the lower the level of internet anxiety and the lower a student's reactive/generative self-efficacy, the higher the level of internet anxiety. It is noteworthy that while the proportion of variance in internet anxiety scores uniquely explained by reactive/generative self-efficacy was statistically significant, it was not large in magnitude. Despite this, we believe the finding does have theoretical and practical value.

As pointed out earlier, the task to build knowledge with one's peers through reaction and generation necessarily involves argumentation. The process of argumentation calls for manipulation of knowledge to respond to others' viewpoints (i.e., reaction) while simultaneously building and expressing one's own perspective on the topic at hand (i.e., generation). The two facets of argumentation are interdependent and must be performed in conjunction with each other. The interaction among reaction and generation during blogging characterises the knowledge building process with a high level of intrinsic cognitive load (Sweller et al., 1998). In fact, research suggests that irrespective of age, most individuals are prone to expounding their own perspective at the cost of ignoring the perspective of others' (Kuhn \& Udell, 2007). According to Kuhn and Udell, this observation is largely a consequence of lack of expertise with respect to argumentation. With increasing level of expertise, the cognitive load of knowledge construction through argumentation seems less overwhelming. On a related note, it is pertinent to mention that Kim and Glassman (2013) suggested most students lack mastery experiences or expertise with reactive/generative skills because day-to-day interactions with the web do not present opportunities to exercise these skills. From the standpoint of the socio-cognitive theory, this increases the possibility that most students will lack self-efficacy with regard to reactive/generative skills in the absence of adequate mastery. Bandura (1988) suggests that when people believe that the demands of a situation exceeds their perceived capacity for handling the situation successfully, the likelihood of experiencing anxiety arousal is high. Consequently, Bandura's socio-cognitive theory can explain our findings. The requirement placed on the learners in this course to respond thoughtfully to others' blog posts (react) and create educationally valuable posts regarding topics on child development (generate), is demanding (i.e., high intrinsic load) and may result in producing internet anxiety for learners who do not have high reactive/generative self-efficacy. On the other hand, learners who believe they will be able to apply reactive/generative skills appropriately, will experience less internet anxiety. The results from the regression analysis are consistent with this theoretical assumption.

Additionally, the results partially support Kim and Glassman's (2013) idea of three levels of self-efficacy with regard to internet skills. Their classification is based on the socio-cognitive concept of mastery experience. Specifically, they suggest that students do not have as many opportunities to gain mastery experiences in using reactive/generative skills compared to communication skills, search skills, organisation skills, and differentiation skills. Lack of mastery experiences leads to lower self-efficacy (Bandura, 1977) and greater anxiety (Bandura, 1997). Thus, it is to be expected that in a blog-centric learning environment, where 
reactive/generative skills are mandatory, reactive/generative self-efficacy will be more strongly associated with internet anxiety compared to self-efficacy for other internet related skills. Reactive/generative skills entail a novel way of interacting with others as they are more focused on co-construction of knowledge as opposed to simple communication. This is supported by research showing that students using the web within educational settings might experience internet anxiety while engaging in online communication characterised by a need for exercising new skills (Caspi, Chajut, \& Saporta, 2008; Ng, 2011). The results confirm the unique role of reactive/generative self-efficacy in predicting internet anxiety over and above the other predictors (communication self-efficacy, organisation self-efficacy, and differentiation self-efficacy) and provide partial empirical validation to Kim and Glassman's (2013) classification considering search self-efficacy also emerged as a unique predictor in this study.

The practical significance of the results with respect to the unique influence of reactive/generative self-efficacy stems from the evidence that it has the potential to change over time as a function of the contextual affordances and pedagogical support made available by instructors (Kim, Glassman, Bartholomew, \& Hur, 2013). Kim et al. compared two groups of students using a pre-post experimental design and found that students in a blogcentric class with instructor support experienced significant gains in reactive/generative self-efficacy at the end of the semester, whereas students in a class that included web-related tasks that were comparatively much less demanding of reactive/generative skill usage and offered minimal instructor support, did not show a similar gain. If reactive/generative self-efficacy can increase with time under the right circumstances, it opens up the possibility that its contribution to internet anxiety may increase over a time period as students are required to use reactive/generative skills more frequently and perhaps perceive them to be more important and complex with time. The current findings are preliminary but can serve to justify the value of future research aimed at exploring the nature of the relationship between the reactive/generative self-efficacy and internet anxiety at different time points in an academic semester.

It might seem surprising that despite blogging involving online communication, communication self-efficacy did not emerge as a predictor of internet anxiety in and of itself. It is important to point out here that there is an important difference between communication skills and reactive/generative skills. While the former is used more often in everyday interactions with the internet, the latter is not (Kim \& Glassman, 2013). This assumption was empirically validated by Kim et al.'s (2013) study indicating a lack of change in communication selfefficacy within blog-centric courses over time as well as a lack of difference in communication self-efficacy between a blog-centric class and a more traditional class; implying that present day students have adequate communication self-efficacy to begin with. The socio-cognitive theory assumes that greater number of mastery experiences leads to higher self-efficacy which lowers the experienced anxiety. Therefore, it is possible that the students in our sample had adequate communication self-efficacy to begin with and thus, it proved to be inconsequential to their experience of internet anxiety in the blog-centric course.

\section{Search self-efficacy}

Despite past research showing that students score high on search self-efficacy possibly because they use search skills extensively in their everyday activities on the web (Kim \& Glassman, 2013), search self-efficacy emerged as a unique predictor of internet anxiety in the present study. One way of comprehending the results of the analysis is that even though information search is a frequently used internet skill, in an educational context it can involve more complexity than everyday searches on the internet. Also, research on the relationship between search skills and internet anxiety shows that the inability to find pertinent key words and narrow down search terms may increase internet anxiety (e.g., Branch, 2001). Especially in an educational context, students experience anxiety when seeking information in libraries, on the internet, and while thinking about the search process (Abdullah, Erfanmanesh, \& Karim, 2013; Yang, 2001a, 2001b). Thus, the results of this study validate a call for re-examination of the classification of the different aspects of internet self-efficacy into three different levels based on the socio-cognitive notion of mastery experience (Kim \& Glassman, 2013). In the classification, search self-efficacy was placed at the lowest level in the hierarchy because the likelihood of students' usage of search skills in their regular interaction with the internet was considered high, leading to more opportunities for mastery. In the light of the results, it would seem that it is inaccurate to place search self-efficacy at the lowest 
level of mastery in all contexts. Though students may indeed have more experience with search skills in their everyday life, it is unlikely that they search for information as specific and complex in their day-to-day activities when compared to academic contexts. The cognitive complexity of using search skills in the blog-centric classroom lies in the fact that the overall purpose of the online search for information in this course was to be able to build a reliable body of knowledge on child development. More importantly, students in this setting not only have to search for information supporting their own claims but also find information that can successfully challenge others' claims in order to create a trustworthy knowledge base.

While search self-efficacy predicted internet anxiety, differentiating self-efficacy and organisation self-efficacy did not. Differentiation and organisation of information are skills that higher education students are familiar with through traditional classroom activities (Kim et al., 2013), thus, self-efficacy for these skills fails to predict internet anxiety after controlling for search self-efficacy. Applying the socio-cognitive theory to understand this, a possible conclusion is that students in higher education have considerable mastery over organisation and differentiation of information owing to direct experiences with these skills in their offline educational activities. In other words, once they find the relevant information, it is likely that they believe they will be able to transfer their organisation and differentiation skills from their face-to-face classroom environment to the online context. It would appear that believing in the ability to find the right information is more critical in this type of learning environment than other internet related skills.

\section{Implication for educators}

The results have important implications for educators who use web-based activities in conjunction with faceto-face classroom processes to enhance the educational experience of the students. However, mere exposure does not guarantee that learners will master how to use the internet effectively, instead it can increase anxiety (Cowan et al., 2009; Sam, Othman, \& Norman, 2005). Human interaction is important when learning to use information resources (Van Scyoc, 2003), highlighting the need for educators' active involvement in fostering students' search self-efficacy and reactive/generative self-efficacy. Teachers can build a positive attitude toward internet use in education among students by providing high quality experiences to increase the frequency of behaviors (e.g., keeping track of useful information sources and sharing information with peers) which are associated with search skills and reactive/generative skills (Duggan, Hess, Morgan, Kim, \& Wilson, 2001). Educators can utilise technological tools to give useful feedback to students on their search strategies to build search self-efficacy (Hwang, Tsai, Tsai, \& Tseng, 2008). They can build a respectful virtual environment where students feel their identity is valued and set clear standards for quality of information to be shared so that learners can expect to improve their academic performance (Chou, 2010; Cowan et al., 2009) through exercise of reactive/generative skills and at the same time build self-efficacy for the same. Active involvement is critical if educators desire to minimise internet anxiety which impacts learning outcomes negatively and reduces internet use in students in the absence of support (Brosnan et al., 2012; Joiner et al., 2007).

Considering that the level of expertise of students with respect to reactive/generative skills and search skills vary over time (Kim \& Glassman, 2013), it is also important that the instructional style is modified accordingly. When learning involves complex tasks, it is an effective instructional strategy to artificially reduce the intrinsic cognitive load (van Merrinboer \& Sweller, 2005). While it is impossible to actually reduce the intrinsic load of a complex task, starting out by presenting the components of the task in an isolated manner in the early stages of learning and gradually adding to the level of complexity as expertise increases has proven to be an effective instructional move (Pollock, Chandler, \& Sweller, 2002; Regeiluth, 1999; van Merrienboer, 1997). In a blogcentric class, it might be useful to devote separate phases of the course to learning how to apply each of the internet related skills - search skills, reactive skills, and generative skills, prior to asking students to use them all at once (i.e., whole task sequencing). While their understanding of the process of collaborative knowledge building may have gaps in the initial stages, the elements will start to assume greater meaning in relation to each other when whole task sequencing is employed (Goettl \& Shute, 1996; Peck \& Detweiler, 2000; van Merrienboer, 1997). Instructors need to monitor student progress very carefully to be able to gauge whether students are developing mastery as a result of breaking down the complex task into simpler parts. In the event of this strategy proving ineffectual, cognitive load theory would suggest breaking down the elements into even 
simpler components. It is crucial that breaking down the task of knowledge construction into its constituent parts is done thoughtfully such that students are ultimately able to form an accurate schema of the knowledge sharing process.

Developing students' self-efficacy with respect to search skills and reactive/generative skills is of paramount importance given that these skills are not only becoming crucial to successful experiences in higher education but also critical for functioning adequately as an active and engaged member of the evolving society. Research suggests that information seeking on the Internet is positively related to academic performance (Zhu, Chen, Chen, \& Chen, 2011) and online information seeking (search skills) and participation in online community discussions (reactive/generative skills) is positively linked with civic engagement (Moy, Manosevitch, Stamm, Dunsmore, 2005). As the number and quality of online personal services grows (Fisher \& Bendas-Jacob, 2006), learners today will need self-efficacy with respect to search skills and reactive/generative skills in order to function as active community members in the future.

\section{Limitations and future directions}

Our findings provide support to the viewpoint that the relationship between internet self-efficacy and internet anxiety is better understood through a nuanced approach and offer a starting point to think about teaching strategies within web-assisted constructivist learning environments. However, there are three existing limitations that we would like to point out as well as suggest ways in which that can be addressed in future research.

First, the overall amount of variance explained by the regression model is low despite being statistically significant. From a methodological perspective when assessed efficacy beliefs do not correspond closely to the task, then their predictive value is diminished (Pajares, 1995). In our study, other than items on the reactive/generative subscale, none of the items in the ISS specifically refers to the blog-centric context of the class. This may have been partially responsible for the low amount of variance explained in internet anxiety scores. In future research, efforts should be made to design assessment items that contextualise the skills as closely as possible within the specific web-assisted educational environment being studied. Another reason that may have contributed to the low amount of variance explained, is the lack of additional predictors in the model that may potentially interact with the different components of internet self-efficacy. For example, students' beliefs and perceptions of the importance of web-related skills and perceived instructional support, are important correlates of internet anxiety and have the potential to interact with the different predictors in our model (Thatcher, Loughry, Lim, \& McKnight, 2007). Future investigations should incorporate these factors in the prediction model as covariates to enhance current understanding of what contributes to internet anxiety.

Second, the ISS (Kim \& Glassman, 2013) and the internet anxiety scale (Kim \& Glassman, 2013; Spielberger et al., 1980) were not pilot tested prior to the present study. While the reliability values for these instruments were reported, factor analysis was not conducted to validate the measures with the current sample. Kim and Glassman conducted a confirmatory factor analysis to validate the ISS and observed a good model fit for the five factor structure. However, two of the subscales of ISS, communication self-efficacy and search selfefficacy, have two items each. Within the factor analysis literature, while three items per factor is considered more desirable for scale validity (Hair et al., 2006), the two indicator rule states that having two items per factors is a sufficient condition when the scale has multiple factors (Bollen, 1989; Kenny, 2011; Kline, 2011). The internet anxiety scale used in the present study was a modified version of the STAI. It is common practice among educational researchers to adapt items on the STAI to match their research context and only report reliability values (e.g., Black \& Deci, 2000; Hall \& Webb, 2011; Kim \& Glassman, 2013). Future empirical work using these scales should consider conducting factor analysis to ensure greater methodological rigor.

Third, the scope of the results is limited because the sample mostly comprised of students who were native English language speakers, and student learning outcomes was not measured. In other words, to improve generalisability future studies should include non-native English speakers and direct assessment of learning outcomes. 


\section{Conclusion}

Our work presents a nuanced understanding of what predicts internet anxiety in learners and highlights the need for providing educational support to minimise internet anxiety. From a theoretical viewpoint the unique value of reactive/generative self-efficacy in predicting internet anxiety is consistent with the socio-cognitive assumptions about the relationship between mastery experience, self-efficacy, and anxiety. The unexpected yet interesting finding pertaining to the unique relevance of search self-efficacy in this context indicates that the assumptions regarding the three levels of internet related self-efficacy based on the significance of mastery experiences in the socio-cognitive theory (Kim \& Glassman, 2013) need to be revisited and revised to incorporate the influence of the nature of web-assisted learning contexts. From a practical viewpoint, the results proffer a reason to begin thinking consciously about teaching strategies in web-assisted constructivist learning environments which call for student participation in online knowledge creation. In conclusion, the findings are sufficiently intriguing to warrant further research aimed at improving our current knowledge regarding the relationship between internet self-efficacy and internet anxiety.

\section{References}

Abdullah, A., Erfanmanesh, M., \& Karim, N. H. A. (2013). Information seeking anxiety: Concept, measurement and preliminary research. International Journal of Information Science and Management, 12(1), 47-64. Retrieved from http://repository.um.edu.my/37517/1/Amin-2014.pdf

Aydin, S. (2011). Internet anxiety among foreign language learners. TechTrends: Linking Research \& Practice to Improve Learning, 55(2), 46-54. https://doi.org/10.1007/s11528-011-0483-y

Bandura, A. (1986). Social foundations of thought and action: A social cognitive theory. Englewood Cliffs, NJ: Prentice-Hall.

Bandura, A. (1988). Self-efficacy conception of anxiety. Anxiety Research, 1(2), 77-98. https://doi.org/10.1080/10615808808248222

Bandura, A. (1997). Self-efficacy: The exercise of control. New York, NY: Freeman.

Bandura, A. (2006). Toward a psychology of human agency. Perspectives on Psychological Science, 1(2), 164-180. https://doi.org/10.1111/j.1745-6916.2006.00011.x

Benkler, Y. (2006). The wealth of networks: How social production transforms markets and freedom. New Haven, CT: Yale University Press.

Bollen, K. (1989). Structural equations with latent variables. New York, NY: John Wiley \& Sons.

Black, A.E., \& Deci, E.L. (2000). The effects instructor's autonomy support and students' autonomous motivation on learning organic chemistry: A self-determination theory perspective. Science Education, 84(6), 740-756. https://doi.org/10.1002/1098-237X(200011)84:6<740::AID-SCE4>3.0.CO;2-3

Branch, J. L. (2001). Information seeking process of junior high school students: A case study of CD-ROM encyclopedia use. School Libraries Worldwide, 7(1), 11-27. Retrieved from http://web.a.ebscohost.com.proxy.lib.ohio-state.edu/ehost/pdfviewer/pdfviewer?sid=8934a894-36e84238-b786-5d7356a605a3\%40sessionmgr4001\&vid=1\&hid=4212

Brosnan, M., Joiner, R., Gavin, J., Crook, C., Maras, P., Guiller, J., \& Scott, A. J. (2012). The impact of pathological levels of internet-related anxiety on internet usage. Journal of Educational Computing Research, 46(4), 341-356. https://doi.org/10.2190/EC.46.4.b

Caspi, A., Chajut, E., \& Saporta, K. (2008). Participation in class and in online discussions: Gender differences. Computers \& Education, 50(3), 718-724. https://doi.org/10.1016/j.compedu.2006.08.003

Castells, M. (2007). Communication, power and counter-power in the Network society. International Journal of Communication, 1, 238-266. Retrieved from http://ijoc.org/index.php/ijoc/article/viewArticle/46

Castells, M., Tubella, I., Sancho, T., Diaz ed Isla, M., \& Wellman, B. (2004). Social structure, cultural identity, and personal autonomy in the practice of the internet: The network society in Catalonia. In M. Castells (Ed.), The network society: A cross-cultural perspective (pp. 233-248). Cheltenham, UK: Edward Elgar.

Charlton, J. P., \& Morahan-Martin, J. (2012). Digital pathologies in education: Introduction to the special issue. Journal of Educational Computing Research, 46(4), 335-339. https://doi.org/10.2190/EC.46.4.a 
Cheung, W., \& Huang, W. (2005). Proposing a framework to assess internet usage in university education: An empirical investigation from a student's perspective. British Journal of Educational Technology, 36(2), 237-253. https://doi.org/10.1111/j.1467-8535.2005.00455.x

Chou, C. (2003). Incidences and correlates of Internet anxiety among high school teachers in Taiwan. Computers in Human Behavior, 19(6), 731-749. https://doi.org/10.1016/S0747-5632(03)00010-4

Chou, S. W. (2010). Why do members contribute knowledge to online communities? Online Information Review, 34(6), 829-854. https://doi.org/10.1108/14684521011099360

Chuang, S. C., \& Tsai, C. C. (2005). Preferences toward the constructivist internet-based learning environments among high school students in Taiwan. Computers in Human Behavior, 21(2), 255-272. https://doi.org/10.1016/j.chb.2004.02.015

Compeau, D., \& Higgins,C. A. (1995).Computer self-efficacy: Development of a measure and initial test. MIS Quarterly, 19(2), 189-211. https://doi.org/10.2307/249688

Cowan, B. R., Vigentini, L., \& Jack, M. A. (2009). Exploring the effects of experience on wiki anxiety and wiki usability: an online study. Proceedings of the 23rd BCS Conference on Human Computer Interaction (pp. 175-183). Cambridge, UK: ACM. Retrieved from http://benjamincowan.com/BCSHCI2009_Final.pdf

Derakshan, N., \& Eysenck, M. W. (2009). Anxiety, processing efficiency, and cognitive performance: New developments from attentional control theory. European Psychologist, 14(2), 168-176. https://doi.org/10.1027/1016-9040.14.2.168

Du, H. S. \& Wagner, C. (2007). Learning with weblogs: Enhancing cognitive and social knowledge construction. IEEE Transactions on Professional Communication, 50(1), 1-16. https://doi.org/10.1109/TPC.2006.890848

Duggan, A., Hess, B., Morgan, D., Kim, S., \& Wilson, K. (2001). Measuring students' attitudes toward educational use of the internet. Journal of Educational Computing Research, 25(3), 267-282. https://doi.org/10.2190/GTFB-4D6U-YCAX-UV91

Eastin, M. S., \& LaRose, R. (2000). Internet self-efficacy and the psychology of the digital divide. Journal of Computer-Mediated Communication, 6(1). https://doi.org/10.1111/j.1083-6101.2000.tb00110.x

Ebner, M. \& Zechner, J. \& Holzinger, A. (2006). Why is Wikipedia so successful? Experiences in establishing the principles in higher education. Proceedings of I-KNOW 06, 6th International Conference on Knowledge Management, Graz, Austria. Retrieved from http://citeseerx.ist.psu.edu/viewdoc/download?doi=10.1.1.148.9876\&rep=rep1\&type=pdf

Fisher, Y., \& Bendas-Jacob, O. (2006). Measuring internet usage: The Israeli case. International Journal of Human-Computer Studies, 64(10), 984-997. https://doi.org/10.1016/j.ijhcs.2006.05.003

Gardner, H. (2008). The mind's new science: A history of the cognitive revolution. New York, NY: Basic Books.

Glassman, M. (1996). The argument for constructivism. American Psychologist, 51(3), 264-265. https://doi.org/10.1037/0003-066X.51.3.264

Glassman, M. (2016). Educational Psychology and the Internet. New York, NY: Cambridge University Press.

Glassman, M., \& Kang, M. J. (2011). The logic of wikis: The possibilities of the Web 2.0 classroom. International Journal of Computer-Supported Collaborative Learning, 6(1), 93-112. https://doi.org/10.1007/s11412-011-9107-y

Glassman, M., \& Kang, M. J. (2012). Intelligence in the internet age: The emergence and evolution of open source intelligence (OSINT). Computers in Human Behavior, 28(2), 673-682. https://doi.org/10.1016/j.chb.2011.11.014

Goettl, B. P., \& Shute, V. J. (1996). Analysis of part-task training using the backward-transfer technique. Journal of Experimental Psychology: Applied, 2(3), 227-249. https://doi.org/10.1037/1076-898x.2.3.227

Hall, N., \& Webb, D. (2014). Instructor's support of student autonomy in an introductory physics course. Physical Review Special Topics-Physics Education Research, 10(2), 1-22. https://doi.org/10.1103/physrevstper.10.020116

Heinssen, R. K., Glass, C. R., \& Knight, L. A. (1987). Assessing computer anxiety: Development and validation of the computer anxiety rating scale. Computers in Human Behavior, 3(1), 49-59. https://doi.org/10.1016/0747-5632(87)90010-0 
Hwang, G. J., Tsai, P. S., Tsai, C. C., \& Tseng, J. C. (2008). A novel approach for assisting teachers in analyzing student web-searching behaviors. Computers \& Education, 51(2), 926-938.

https://doi.org/10.1016/j.compedu.2007.09.011

Joiner, R., Brosnan, M., Duffield, J., Gavin, J., \& Maras, P. (2007). The relationship between internet identification, internet anxiety and internet use. Computers in Human Behavior, 23(3), 1408-1420. https://doi.org/10.1016/j.chb.2005.03.002

Joiner, R., Gavin, J., Duffield, J., Brosnan, M., Crook, C., Durndell, A., ... Lovatt, P. (2005). Gender, internet identification, and internet anxiety: Correlates of internet use. CyberPsychology \& Behavior, 8(4), 371378. https://doi.org/10.1089/cpb.2005.8.371

Kenny, D. (2011) Identification: Overview. Retrieved from http://davidakenny.net/cm/identify.htm

Kim, Y., \& Glassman, M. (2013). Beyond search and communication: Development and validation of the internet self-efficacy scale (ISS). Computers in Human Behavior, 29(4), 1421-1429. https://doi.org/10.1016/j.chb.2013.01.018

Kim, Y., Glassman, M., Bartholomew, M., \& Hur, E. H. (2013). Creating an educational context for Open Source Intelligence: The development of Internet self-efficacy through a blogcentric course. Computers \& Education, 69, 332-342. https://doi.org/10.1016/j.compedu.2013.07.034

Kline, R. B. (2011). Principles and practice of structural equation modeling (3rd ed.). New York, NY: Guilford Press.

Kuhn, D., \& Udell, W. (2007). Coordinating own and other perspectives in argument. Thinking \& Reasoning, 13(2), 90-104. https://doi.org/10.1080/13546780600625447

Lang, P. J. (1977). Physiological assessment of anxiety and fear. In J. D. Cone \& R. P. Hawkins (Eds.), Behavioral assessment: New directions in clinical psychology (pp. 178-195). New York, NY: Brunner/Mazel.

Liang, J. C., \& Tsai, C. C. (2008). Internet self-efficacy and preferences toward constructivist internet-based learning environments: A study of pre-school teachers in Taiwan. Educational Technology \& Society, 11(1), 226-237. Retrieved from http://www.jstor.org/stable/jeductechsoci.11.1.226

Moy, P., Manosevitch, E., Stamm, K., \& Dunsmore, K. (2005). Linking dimensions of internet use and civic engagement. Journalism \& Mass Communication Quarterly, 82(3), 571-586. https://doi.org/10.1177/107769900508200306

$\mathrm{Ng}$, K. C. (2001). Using e-mail to foster collaboration in distance education. Open Learning, 16(2), $191-200$. https://doi.org/10.1080/02680510120050343

O’Reilly, T. (2005). What is Web 2.0: design patterns and business models for the next generation of software. Retrieved from http://www.oreilly.com/pub/a/web2/archive/what-is-web-20.html

Pajares, F. (1996). Self-efficacy beliefs in academic settings. Review of Educational Research, 66(4), 543578. https://doi.org/10.3102/00346543066004543

Peck, A. C., \& Detweiler, M. C. (2000). Training concurrent multistep procedural tasks. Human Factors, 42(3), 379-389. https://doi.org/10.1518/001872000779698150

Peng, H., Tsai, C. C., \& Wu, Y. T. (2006). University students’ self-efficacy and their attitudes toward the Internet: The role of students’ perceptions of the Internet. Educational Studies, 32(1), 73-86. https://doi.org/10.1080/03055690500416025

Pollock, E., Chandler, P., \& Sweller, J. (2002). Assimilating complex information. Learning and Instruction, 12(1), 61-86. https://doi.org/10.1016/S0959-4752(01)00016-0

Presno, C. (1998). Taking the byte out of internet anxiety: Instructional techniques that reduce computer/internet anxiety in the classroom. Journal of Educational Computing Research, 18(2), 147-161.

Reigeluth, C. M. (1999). The elaboration theory: Guidance for scope and sequence decisions. In C, M. Reigeluth, (Ed.), Instructional design theories and models: A new paradigm of instructional theory (Vol. 2, pp. 424-453). Erlbaum, Mahwah, NJ.

Rezai, M., \& Shams, A. (2014). Correlates of internet anxiety among agricultural students in Zanjan University of Iran. Journal of Educational and Instructional Studies in the World, 4(1), 63-70. Retrieved from http://wjeis.org/FileUpload/ds217232/File/08a.rezaei.pdf

Sam, H. K., Othman, A. E. A., \& Nordin, Z. S. (2005). Computer self-efficacy, computer anxiety, and attitudes toward the internet: A Study among undergraduates in Unimas. Educational Technology \& Society, 8(4), 205-219. Retrieved from http://www.nottingham.ac.uk/ ntzcl1/literature/attitudes/sam.pdf 
Spielberger, C. D., Vagg, P. R., Barker, L. R., Donham, G. W., \& Westberry, L. G. (1980). Factor structure of the State-Trait anxiety inventory. In I. G. Sarason \& C. D. Spielberger (Eds.), Stress and anxiety (Vol 7, pp. 95-109). Washington, DC: Hemisphere.

Susskind, A. M. (2004). Electronic commerce and the world wide web apprehensiveness: An examination of consumers' perceptions of the world wide web. Journal of Computer-Mediated Communication, 9(3). https://doi.org/10.1111/j.1083-6101.2004.tb00287.x

Sweller, J., van Merrienboer, J. J., \& Paas, F. G. (1998). Cognitive architecture and instructional design. Educational Psychology Review, 10(3), 251-296. https://doi.org/10.1023/A:1022193728205

Thatcher, J. B., Loughry, M. L., Lim, J., \& McKnight, D. H. (2007). Internet anxiety: An empirical study of the effects of personality, beliefs, and social support. Information \& Management, 44(4), 353-363. https://doi.org/10.1016/j.im.2006.11.007

Torkzadeh, G., \& Van Dyke, T. P. (2001). Development and validation of an internet self-efficacy scale. Behaviour and Information Technology, 20(4), 275-280. https://doi.org/10.1080/01449290110050293

Tsai, C. C. (2008). The preferences toward constructivist internet-based learning environments among university students in Taiwan. Computers in Human Behavior, 24(1), 16-31. https://doi.org/10.1016/j.chb.2006.12.002

Tsai, C. C., Chuang, S. C., Liang, J. C., \& Tsai, M. J. (2011). Self-efficacy in internet-based learning environments: A literature review. Educational Technology \& Society, 14(4), 222-240. Retrieved from http://www.ifets.info/journals/14_4/19.pdf

Tsai, M. J., \& Tsai, C. C. (2003). Information searching strategies in web-based science learning: The role of internet self-efficacy. Innovations in Education and Teaching International, 40(1), 43-50. https://doi.org/10.1080/1355800032000038822

van Merrienboer, J. J. G. (1997). Training complex cognitive skills. Englewood Cliffs, NJ: Educational Technology Publications.

van Merrienboer, J. J., \& Sweller, J. (2005). Cognitive load theory and complex learning: Recent developments and future directions. Educational Psychology Review, 17(2), 147-177. https://doi.org/10.1007/s10648-005-3951-0

Van Scoyoc, A. M. (2003). Reducing library anxiety in first-year students: the impact of computer-assisted instruction and bibliographic instruction. Reference \& User Services Quarterly, 42 (4) 329-341. Retrieved from http://web.a.ebscohost.com.proxy.lib.ohio-state.edu/ehost/pdfviewer/pdfviewer?sid=23d670fc-5ced4d83-bb00-eda35f8d1e87\%40sessionmgr4005\&vid=3\&hid=4212

Wu, Y. T., \& Tsai, C. C. (2006). University students' internet attitudes and internet self-efficacy: A study at three universities in Taiwan. CyberPsychology \& Behavior, 9(4), 441-450. https://doi.org/10.1089/cpb.2006.9.441

Yang, S. C. (2001a). Language learning on the world wide web: An investigation of EFL learners' attitudes and perceptions. Journal of Educational Computing Research, 24(2), 155-181. https://doi.org/10.2190/VDJC-FGTQ-79FH-M615

Yang, S. C. (2001b). Integrating computer-mediated tools into the language curriculum. Journal of Computer Assisted Learning, 17(1), 85-93. https://doi.org/10.1111/j.1365-2729.2001.00161.X

Zhu, Y. Q., Chen, L. Y., Chen, H. G., \& Chern, C. C. (2011). How does internet information seeking help academic performance? The moderating and mediating roles of academic self-efficacy. Computers \& Education, 57(4), 2476-2484. https://doi.org/10.1016/j.compedu.2011.07.006

Corresponding author: Narmada Paul, paul.828@osu.edu

Australasian Journal of Educational Technology (c) 2017.

Please cite as: Paul, N., \& Glassman, M. (2017). Relationship between internet self-efficacy and internet anxiety: A nuanced approach to understanding the connection. Australasian Journal of Educational Technology, 33(4), 147-165. https://doi.org/10.14742/ajet.2971 


\section{Appendix A}

Communication self-efficacy

1. I can use social networking sites as an effective way of connecting with others.

2. I can be very effective communicating using social networking sites like Facebook.

Search self-efficacy

1. I can use the internet to help me find good information about children and their development.

2. I can use the internet to find good information about topics that are important to me.

Organisation self-efficacy

1. I can use the internet to answer other people's questions in a productive way.

2. I can use the internet to answer my own questions in a productive way.

3. I can organise the information I find on the internet so that it is coherent and answers specific questions.

Differentiation self-efficacy

1. I can improve my own well-being through the use of hyperlinks.

2. I can use hyperlinks to find information that is important to others.

3. I can use hyperlinks to find information that is important to me.

4. I can improve others' well-being through the use of hyperlinks.

Reactive/generative self-efficacy

1. I can use blogging as an effective way of connecting with others.

2. I can write blog posts that other people will read and be interested in.

3. I can be very effective using blogging sites like blogger.

4. I can have a positive impact on the lives' of others through blogging.

5. I can offer other people important and interesting information by posting on the Internet.

6. I can find important and interesting information by reading other people's blogs. 


\section{Appendix B}

1. I feel calm when I need to find new information on my own.

2. I feel secure about sharing my thoughts with others.

3. I feel tense when I think about blogging being a course requirement.

4. I feel strained having to write online every week.

5. I feel at ease writing what I think for other people to read.

6. I feel upset when other people comment on my work.

7. I feel satisfied when I have said something I really wanted to say in a blog post.

8. I feel frightened when I think people I do not know will read my work.

9. I feel uncomfortable with public discussion of ideas.

10. I feel self-confident that people will like what I write online.

11. I feel nervous that people will not like what I write online.

12. I feel jittery that people will judge me because of what I write online.

13. I feel content with my ability to seek out information on the web.

14. I feel indecisive when I am thinking about making one of my ideas public.

15. I am relaxed when I am reading other people's blog posts.

16. I am worried when I am reading other people's comments on what I wrote.

17. I am confused when I am asked to write a blog post on a subject.

18. I am presently worrying over possible misfortunes.

19. I feel steady when I hit the "post/submit"' button.

20. I feel pleasant when my blog posts are recognised in the class. 